\title{
Investigamos la
}

producción natural de

lágrimas contra el ojo seco

- Alicia de Lara

7 uana Gallar, actual subdirectora del Instituto de Neurociencias, investiga los

mecanismos que se producen cuando tiene lugar la sensación de dolor. El equipo de Neurobiología Ocular de la UMH analiza cómo las neuronas sensoriales hacen frente a los diferentes estímulos y procesos que evocan esta desagradable percepción, según el tipo de tejido. La parte concreta que utilizan como modelo es la córnea, lo que les ha llevado a especializarse en patologías oftalmológicas como el ojo seco, una enfermedad que padecen personas con deficiencia de producción lagrimal quienes experimentan malestar y picor. Se trata de la más común de las afecciones oculares y para la que, hoy por hoy, se carece de cura.

Pregunta: ¿Es posible medir el dolor? Respuesta: No existen mecanismos absolutamente objetivos. Se utilizan complejos cuestionarios y técnicas indirectas, pero resulta muy complicado porque la sensación de dolor que percibe el ser humano está fuertemente condicionada por el aprendizaje y la experiencia previa. Se experimenta de forma diferente dependiendo de la cultura. Hace siglos, era algo a lo que había que resignarse, una especie de castigo divino. A día de hoy, las sociedades occidentales son intolerantes con el sufrimiento. Existen también diferencias en la forma de percibir el dolor entre hombres y mujeres. De la misma manera, hemos encontrado desigualdades dependiendo de la edad u otras características epidemiológicas.

\section{P.: ¿Por qué el ojo?}

R.: La señal de dolor, en cualquier organismo vivo, es en realidad un signo de alerta, indica que un estímulo resulta nocivo. La córnea del ojo concentra quinientas veces más densidad de receptores de dolor que cualquier otro lugar del cuerpo, por ejemplo, la piel. Esta es la razón por la que hemos convertido a la córnea en nuestro modelo experimental. Su estudio continuado durante alrededor de treinta años nos ha llevado a interesarnos por problemas oftalmológicos. Hasta el punto de que, a día de hoy, nos centramos en analizar los mecanismos de dolor ocular específicamente y las patologías comunes, como es el caso del ojo seco.
P.: ¿En qué consiste la investigación que su equipo lleva a cabo sobre esta patología?

R.: Hemos desarrollado un modelo experimental con animales, que imita aceptablemente bien la situación del ojo seco que se da en el ser humano. Analizamos cómo se altera la actividad de los nervios en ese proceso crónico que es el ojo seco y lo hacemos en diferentes etapas. De manera paralela, hemos estudiado la sensación que experimentan las personas que padecen la patología, con el empleo de un estesiómetro, instrumento patentado por el Instituto capaz de acercarnos de una manera fiable a la cantidad de sensación dolorosa. Con este aparato conseguimos estimular el tejido de manera controlada para medir el umbral de la sensación de dolor específicamente en la superficie ocular. Los resultados de esta investigación, que ahora se encuentra en su última fase, después de varios años de trabajo, se publicarán muy pronto.

\section{P.: Sin lágrimas el ojo está perdido.}

R.: Su producción y evacuación se produce de forma continua. Lo que posibilita la existencia, en la parte anterior de nuestro ojo, de una fina película lagrimal, con importantes funciones. 


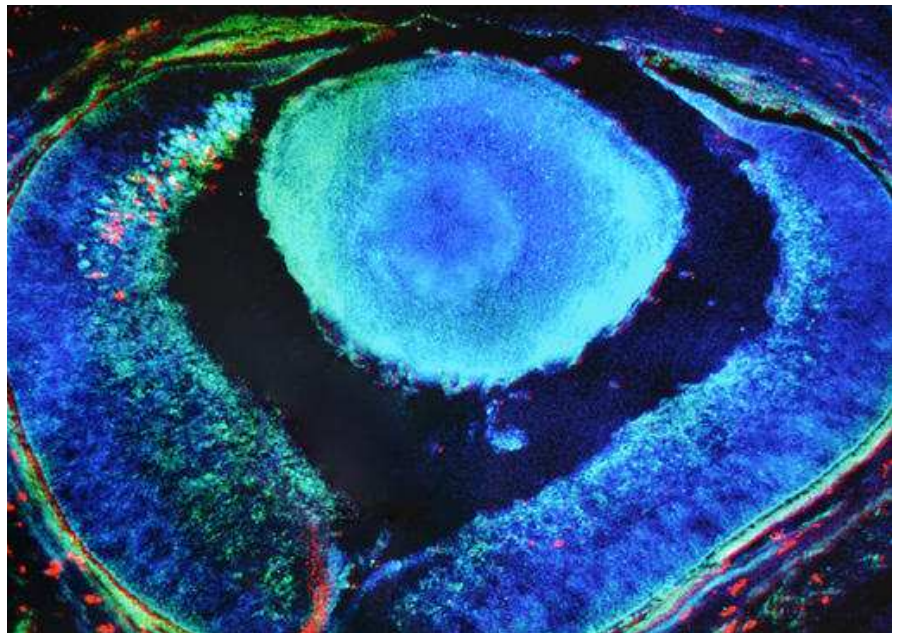

1. Detalle córnea

2. Instrumental de laboratorio

3. Personal investigador del Instituto
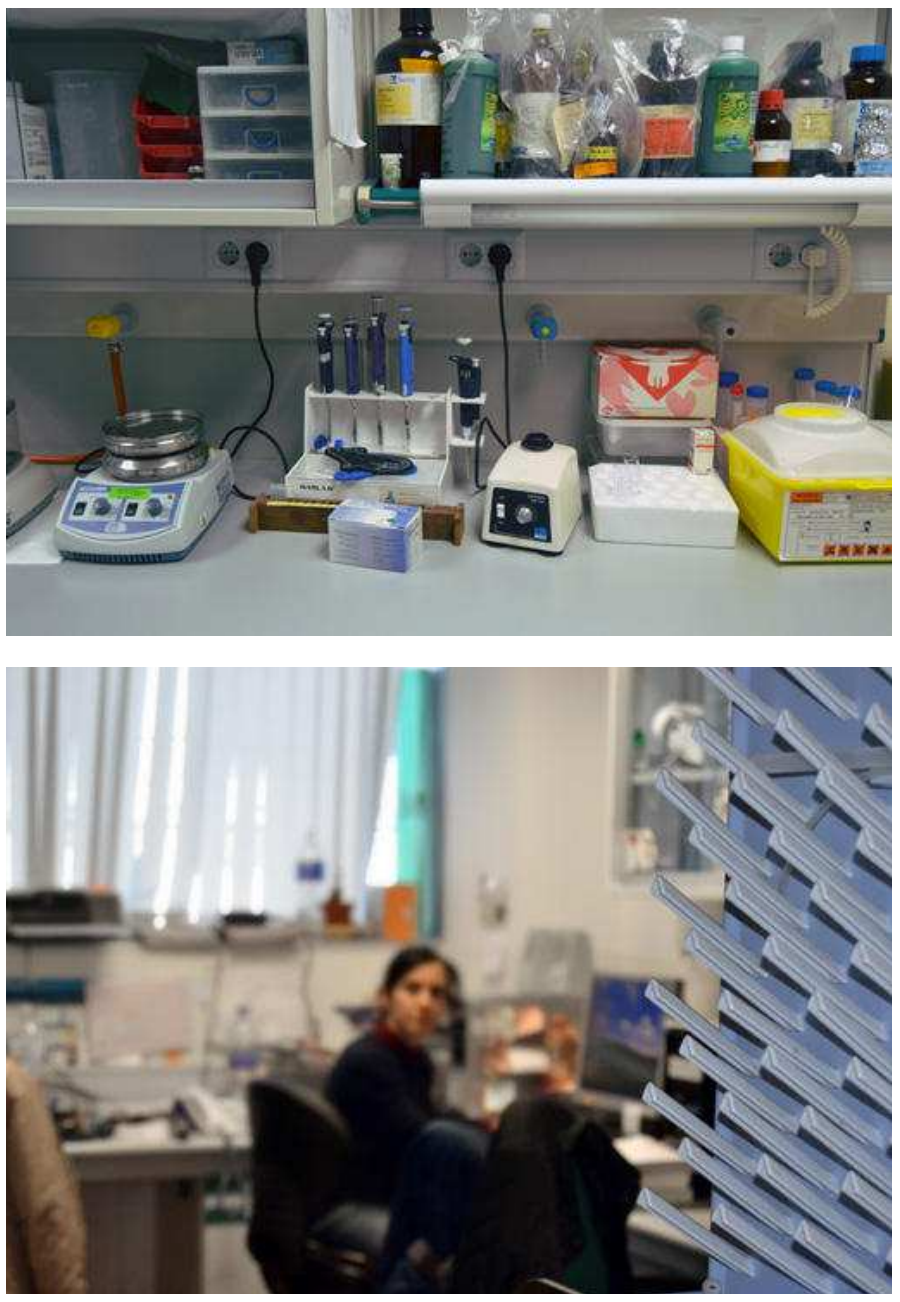

$>$ últimos años se hayan multiplicado de golpe los casos. La principal es la cirugía refractiva. Hemos detectado que este tipo de intervenciones ha provocado un aumento de los casos de ojo seco en personas jóvenes, que no deberían estar dentro del grupo de población de riesgo. De hecho, la mitad de las personas que se han sometido a una operación de miopía desarrollan sensación de ojo seco. Se trata de un efecto colateral que aparece a la semana de que haya tenido lugar la cirugía. Afortunadamente, en algunas de esas personas la patología mejora y al cabo del tiempo disminuye bastante la sensación de ojo seco, pero en un alto porcentaje perdurará durante toda la vida.

\section{P. ¿Hay alguna forma de contrarrestar sus efectos?}

R.: La mejor herramienta que tenemos para hacer frente al ojo seco es parpadear. Por ejemplo, la diferencia entre la lectura en un ordenador y en un libro es que ante la pantalla el ojo está más abierto que cuando lee páginas y, por tanto, menos protegido. Al fijar la atención, nuestro cerebro está preparado para disminuir el parpadeo, una manera de asegurar que no se interrumpe el flujo de información visual que llega al cerebro. Por eso al leer disminuye la frecuencia de parpadeo alrededor de cuatro veces y no se produce la renovación de la película lagrimal. Además, cuando trabajamos frente al ordenador, donde la pantalla suele estar más elevada y lo hacemos a lo largo de varias horas seguidas, el ojo está menos protegido y se produce una mayor evaporación.

\section{P. Entonces, no hay cura...}

R.: No existe ningún fármaco autorizado en el mercado europeo contra el ojo seco. Sí contamos con diversos tratamientos paliativos. Por ejemplo, las lágrimas artificiales de diferentes composiciones, pero todas están muy lejos de poseer las propiedades de las lágrimas reales, la principal: su capacidad de mantener a raya el crecimiento bacteriano. Lo ideal sería encontrar una manera de aumentar la producción natural de lágrimas, una de las principales líneas de investigación ocular del Instituto de Neurociencias. 